\title{
Diaphyseal Humeral Fractures Treated by Bracing versus Dynamic Compression Plate
}

\author{
BHEESHAM KUMAR ${ }^{1}$, ASHOK KUMAR ${ }^{2}$, LACHHMAN DAS MHESHWARI ${ }^{3}$, ZAMIR HUSSAIN TUNIO ${ }^{4}$, RIZWAN ALI \\ JHATIYAL ${ }^{5}$, KHAWAND BUX UMRANI ${ }^{6}$ \\ ${ }^{1}$ Consultant Orthopaedic Surgeon, Taluka Hospital Digri \\ ${ }^{2}$ Medicl Officer, Government Eye Hospital Umerkot \\ ${ }^{3}$ Senior Registrar, ${ }^{4}$ Assistant Professor, Department of Orthopaedic Surgery and Traumatology, Liaquat University of Medical \& Health \\ Sciences, Jasmshoro \\ ${ }^{5}$ Consultant Orthopaedic Surgeon, Syed Abdullah Shah Institute of Medical Science Sehwan \\ ${ }^{6}$ Senior Registrar, Department of Orthopaedic Surgery and Traumatology, Bolan University of Medical \& Health Sciences, Quetta \\ Correspondence to: Dr. Bheesham Kumar, E-mail: bheesham_dr@hotmail.com, Cell: 0332-2661068
}

\begin{abstract}
Objective: To compare the results of humerus shaft fractures treated by functional bracing and dynamic compression plate.

Study Design: Cross sectional comparative study.

Place and Duration of Study: Department of Orthopaedic Surgery \& Traumatology, Liaquat University Hospital Hyderabad/Jamshoro from $1^{\text {st }}$ June 2015 to $31^{\text {st }}$ May 2016.

Methodology: Eighty cases selected from accident emergency department and outpatient departments. Cases were divided in two groups; group A (dynamic compression plate) and group B (functional bracing). Patients of either gender with age range 18-50 years with an isolated closed fracture of the humeral shaft, of duration within 2 weeks and who were willing to participate in the study were included in the study while open fractures, bilateral injuries, poly-trauma, pathological fracture, smoker, alcoholic, immune compromised, and history of poor compliance, psychiatric disease were excluded.

Results: In conservative group, $32(80 \%)$ were males and $8(20 \%)$ females while in dynamic compression plate group, 30 (75\%) were males and 10 (25\%) females with mean age was $35.75 \pm 9.083$ year. There were 46 $(57.5 \%)$ patients who sustained fractures following road traffic accidents $16(20 \%)$ cases had fall from height and $18(22.5 \%)$ cases had after assault. Fracture location was middle third in most of cases in both groups. Mean time for union was $15.45 \pm 2.864$ and $14.325 \pm 3.033$ weeks and mean time of follow-up was $48.35 \pm 6.436$ \& $42.52 \pm 9.33$ weeks in dynamic compression plate and functional bracing groups respectively

Conclusion: Plating of humeral shaft fracture was found to be satisfactory method of treatment with high fracture union rates, better functional outcome [DASH Score] and low complication rate as compared to functional bracing group.

Keywords: Humeus shaft, Fracture, Dynamic compression plate, DASH score, Conservative, Functional bracing
\end{abstract}

\section{INTRODUCTION}

Roughly $1-3 \%$ of every human fracture and $5-10 \%$ of all long bone fractures happen in the humeral shaft. ${ }^{1,2}$ Both surgical as well nonsurgical methods are used to treat these fractures. ${ }^{3}$ Sarmiento casting is documented with better outcome as gold standard option, while the surgical options are nailing, plating and external fixation. Both strategies have their own pros and cons. ${ }^{4,5}$ There is never ending debate and consensus in literature to choose the best method for management. ${ }^{6}$

There are certain absolute and relative surgical indications; poly trauma, bilateral, open and with neurovascular compromise as radial nerve entrapment. ${ }^{7}$ Not long ago newer technique introduced by MIPO method, with two small anterior incisions and application of bridge plate to achieve relative stability and reported good outcomes in cohorts. . $^{8-11}$

The rationale of the study was to add to literature the loco-regional data related to the management of humerus shaft fracture [HSF] with dynamic compression plate (DCP) and conservative methods and compare the results reported from different countries.

\section{MATERIALS AND METHODS}

This cross sectional comparative study was conducted at Department of Orthopaedic Surgery \& Traumatology,
Liaquat University Hospital Hyderabad/Jamshoro from $1^{\text {st }}$ June 2015 to $31^{\text {st }}$ May 2016 and 80 cases were selected from accident \& emergency and outpatient departments. The cases were divided in two groups; group A (dynamic compression plate) and group B (functional bracing). Patients of either gender with age range 18-50 years with an isolated closed fracture of the humeral shaft [HSF], of duration within 2 weeks and who were willing to participate in the study were included in the study while patients older than 55 year and younger than 18 year, open fracture, bilateral injuries, poly-trauma, pathological fracture, smoker, alcoholic, immune compromised, diabetic, on steroids, drug addicted, and history of poor compliance, psychiatric disease were excluded. Patients meeting the selection criteria were explained the purpose of study, procedure to be performed, with merits and demerits and informed consent was obtained.

Group A patients were initially treated with closed reduction and immobilization by application with $U$-slab, after 2 weeks, the $U$ slab was replaced by hanging cast for 2 weeks followed by a functional brace till fracture union. Group B patients were treated by open reduction internal fixation by Henry anterolateral approach with broad $4.5 \mathrm{~mm}$ dynamic compression plate by engaging at least 6 cortices proximal as well distal to fracture. All patients encouraged for movements around shoulder and elbow joint as soon as 
possible except rotation around shoulder joint that was allowed after 6 weeks of fixation. The functional outcome of both groups evaluated by DASH score ${ }^{10}$ [disabilities of the arm, shoulder, and head] by $4^{\text {th }} 8^{\text {th }}, 12^{\text {th }}, 24$ th week, \& one year and scores were compared. In OPD cases assessed thoroughly on clinical and radiological backgrounds every time. Each variable noted on predesigned pro-forma and analyzed by SPSS version 18 .

\section{RESULTS}

In conservative group $32(80 \%)$ were males and $8(20 \%)$ females. In dynamic compression plates (DCP) group 30 (75\%) were males and $10(25 \%)$ females with mean age was $35.75 \pm 9.083$ year. There were $46(57.5 \%)$ patients who sustained fractures following road traffic accidents 16 $(20 \%)$ cases had fall from height and 18 (22.5\%) cases had after assault. Fracture location as middle third in most of cases in both groups. Three $(7.5 \%)$ cases have radial nerve injury in bracing group before injury that neuropraxia recovered with time while none of the case reported radial nerve injury in other group before and after procedure. Regarding $\mathrm{AO}$ classification about half of patients in both groups were classified as simple 12A1, 12A2 and 12A3. In DCP group, $7.5 \%$ cases united within 12 weeks, $67.5 \%$ in $13-16$ weeks, $12.5 \%$ in $17-20$ weeks and $10 \%$ in $21-23$ weeks. In bracing group $27.5 \%$ fracture healed within 12 weeks, $57.5 \%$ in $13-16$ weeks, $10 \%$ in $17-20$ weeks and $5 \%$ in 21-23 weeks. Complications were reported in 10 $(25 \%)$ in the functional brace group and $5(12.5 \%)$ in the plating group. Of the 10 failures in bracing group, 2 (5\%) were due to nonunion, 3 developed malunion, 1 delayed union and $4(10 \%)$ have stiffness of shoulder following casting. Both nonunion cases facilitated with plating with bone graft from iliac crest. While stiff shoulder joint rehabilitated with regular physiotherapy, steroid injection, topical \& oral analgesic as well muscle relaxants. In DCP group superficial surgical site infection was noticed in 2 $(5 \%)$ and dealt with sterilized dressings and culture specific antimicrobials while 1 (2.5\% case developed delayed union that healed without additional surgery, furthermore $2(5 \%)$ presented with stiff shoulder joint that dealt with regular physiotherapy. Average time from injury to hospital arrival was $28.52 \pm 11.43$ hours. The mean time from the injury to functional brace application was $24.25 \pm 6.06$ days. The mean time from the injury to the surgical procedure was $6.45 \pm 3.66$ days. Average hospital stay was $2.4 \pm 1.05$ \& $9.33 \pm 3.74$ days in bracing group \& DCP group respectively (Table 1)

The mean DASH scores were $52.65 \pm 13.53$, $45.77 \pm 26.66,27.28 \pm 29.98,18.63 \pm 15.87$, and $8.35 \pm 4.67$ points at 4 th $, 6^{\text {th }}, 12^{\text {th }}, 24^{\text {th }}$ weeks, and 1 year following functional bracing and 55.68 \pm 10.26 , 40.46 \pm 12.23 , $24.82 \pm 77.46,9.69 \pm 9.85$, and $4.25 \pm 6.78$ points at the respective follow-up periods after treatment with the DCP. Mean time for union was $15.45 \pm 2.864$ \& $14.325 \pm 3.033$ weeks in DCP and casting group respectively. The average time of follow-up was $48.35 \pm 6.436$ and $42.52 \pm 9.33$ weeks in DCP and casting group respectively (Table 2 ).

\section{DISCUSSION}

Though the trend towards surgical management of HSF is escalating day by day because of various factors by high demand of patients for rapid recovery by stable fixation. Huttunen et $\mathrm{al}^{12}$ have observed increasing trend from conservative to surgical methods in HSF even double ratio for men and triple for females.

Shaikh ${ }^{13}$ at Jinnah Postgraduate Medical Centre Karachi evaluated the outcome of DCP in HSF in 65 cases, among them $55.4 \%$ were males \& $44.6 \%$ were females with average age of $36.29 \pm 11.17$ years. RTA most common mode of injury $72.3 \%$ and they observed satisfactory outcome in $86.2 \%$ patients. While in our study conservative group $32(80 \%)$ were males and $8(20 \%)$ females. In dynamic compression plate (DCP) group 30 (75\%) were males and $10(25 \%)$ females with males with mean age was $35.75 \pm 9.083$ year.

Table 1: Comparison between DCP and functional bracing group $(n=80)$

\begin{tabular}{|c|c|c|c|c|}
\hline \multirow{2}{*}{ Variable } & \multicolumn{2}{|l|}{ DCP } & \multicolumn{2}{|c|}{ Functional Bracing } \\
\hline & No. & $\%$ & No. & $\%$ \\
\hline \multicolumn{5}{|l|}{ Gender } \\
\hline Male & 30 & 75.0 & 32 & 80.0 \\
\hline Female & 10 & 25.0 & 8 & 20.0 \\
\hline \multicolumn{5}{|l|}{ Age (years) } \\
\hline $18-35$ & 28 & 70.0 & 22 & 55.0 \\
\hline $36-50$ & 12 & 30.0 & 18 & 45.0 \\
\hline \multicolumn{5}{|l|}{ Mode of injury } \\
\hline Fall & 6 & 15.0 & 10 & 25.0 \\
\hline $\begin{array}{l}\text { R.T.A } \\
\end{array}$ & 24 & 60.0 & 22 & 55.0 \\
\hline Assault & 10 & 25.0 & 8 & 20.0 \\
\hline \multicolumn{5}{|l|}{ AO Classification } \\
\hline $12 \mathrm{~A} 1$ & 8 & 20.0 & 9 & 22.5 \\
\hline $12 \mathrm{~A} 2$ & 7 & 17.5 & 7 & 17.5 \\
\hline $12 \mathrm{~A} 3$ & 5 & 12.5 & 6 & 15.0 \\
\hline 12B1 & 7 & 17.5 & 6 & 15.0 \\
\hline $12 \mathrm{~B} 2$ & 5 & 12.5 & 4 & 10.0 \\
\hline $12 \mathrm{~B} 3$ & 2 & 5.0 & 3 & 7.5 \\
\hline $12 \mathrm{C} 1$ & 3 & 7.5 & 2 & 5.0 \\
\hline $12 \mathrm{C} 2$ & 1 & 2.5 & 2 & 5.0 \\
\hline $12 \mathrm{C} 3$ & 2 & 5.0 & 1 & 2.5 \\
\hline \multicolumn{5}{|l|}{ Location of fracture } \\
\hline $\begin{array}{l}\text { Junction of proximal \& } \\
\text { middle one third }\end{array}$ & 9 & 22.5 & 8 & 20.0 \\
\hline Middle one third & 26 & 65.0 & 23 & 57.5 \\
\hline $\begin{array}{l}\text { Junction of middle \& } \\
\text { distal third }\end{array}$ & 5 & 12.5 & 9 & 22.5 \\
\hline \multicolumn{5}{|l|}{ Time to union (weeks) } \\
\hline 12 & 3 & 7.5 & 11 & 27.5 \\
\hline $13-16$ & 27 & 67.5 & 23 & 57.5 \\
\hline $17-20$ & 5 & 12.5 & 4 & 10.0 \\
\hline $21-23$ & 4 & 10.0 & 2 & 5.0 \\
\hline \multicolumn{5}{|l|}{ Complication } \\
\hline Infection & 2 & 5.0 & - & - \\
\hline Non Union & & 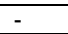 & 2 & 5.0 \\
\hline Delayed union & 1 & 2.5 & 1 & 2.5 \\
\hline Mal-union & - & - & 3 & 7.5 \\
\hline Stiffness of shoulder & 2 & 5.0 & 4 & 10.0 \\
\hline
\end{tabular}

Table 2: Mean DASH score

\begin{tabular}{|l|l|l|}
\hline Duration & DCP & Functional Bracing \\
\hline 4 Weeks & $55.68 \pm 0.26$ & $52.65 \pm 13.53$ \\
\hline 8 Weeks & $40.46 \pm 2.23$ & $45.77 \pm 26.66$ \\
\hline 12 Weeks & $24.82 \pm 77.46$ & $27.28 \pm 29.98$ \\
\hline 24 Weeks & $9.69 \pm 9.85$ & $18.63 \pm 15.87$ \\
\hline Year & $4.25 \pm 6.78$ & $8.35 \pm 4.67$ \\
\hline
\end{tabular}

Matsunaga et $\mathrm{al}^{14}$ in bridge plate and bracing for HSF in 110 patients evaluated the functional outcome by DASH score and compared it by $2^{\text {nd }}, 4^{\text {th }}, 8^{\text {th }}, 24^{\text {th }}$ weeks and by end of year. This trial favored the bridge plate to functional bracing in terms of DASH score nonunion rate $0 \%$ versus $15 \%$. We also observed comparable results that DCP 
group had better DASH score. While in our study the mean DASH scores were $52.65 \pm 13.53$, 45.77 \pm 26.66 , $27.28 \pm 29.98,18.63 \pm 15.87$, and $8.35 \pm 4.67$ points at 4 th, $6^{\text {th }}$, $12^{\text {th }}, 24^{\text {th }}$ weeks and 1 year following functional bracing and $55.68 \pm 10.26,40.46 \pm 12.23,24.82 \pm 77.46,9.69 \pm 9.85$ and $4.25 \pm 6.78$ points at the respective follow-up periods after treatment with the DCP. We observed better score with DCP group.

Harkin and Large ${ }^{15}$ reported that $76.2 \%$ cases were managed conservatively, out of that $13 \%$ went in delayed union, $33 \%$ in nonunion while in operated cases $33 \%$ went in delayed union and $4 \%$ in nonunion. In the meta-analysis and systematic review of two randomized clinical trials 150 and ten observational studies 1262 by van de Wall et al $^{16}$ for the conservative versus operative to manage HSF reported nonunion rate was more with non-operative (15.3\%) compared to surgical methods $(6.4 \%)$. Need have re intervention was more with casting (14.3\%) compared to surgical methods (8.9\%). Although average union time \& DASH score were comparable in both strategies.

Serrano et $\mathrm{al}^{17}$ from nine level 1 trauma centers across the United States initially managed non-operatively with a functional brace were reviewed for need of surgery and contributing factors. $29 \%$ cases needed surgical intervention even after getting functional brace management, contributing factors were nonunion (60\%), mal alignment beyond acceptable parameters (24\%), inability to tolerate functional bracing $(12 \%)$, and persistent signs of radial nerve palsy requiring exploration (3.7\%), females as being 1.7 times more likely and alcoholics to be 1.4 times more likely to be converted to surgery. In the present study complications related to union in bracing group, 2 (5\%) were due to nonunion, 3 developed malunion, 1 delayed union and in DCP group, 1 (2.5\%) case developed delayed union and no case witnessed for nonunion.

Lode et $\mathrm{al}^{18}$ reported that $59.38 \%$ were treated surgically and $40.62 \%$ conservatively; reported risk ratio of 2.76 deep infections in the operative group while there was no difference in other aspects.

In a study done by Ali et $\mathrm{al}^{19}$ regarding nonsurgical treatment, reported that comminuted HSF had $89 \%$ union rate regardless of position of fractured fragments. Papasoulis et al ${ }^{20}$ has reviewed the sixteen case series and two comparative series showed the average union time of HSF of 10.7 weeks and conservative method has main drawbacks of residual deformity and joint stiffness. We also observed comparable results in casting group $4(10 \%)$ have stiffness of shoulder following casting and $2(5 \%)$ presented with stiff shoulder joint in DCP group. None of the case reported limited range of motion in elbow joint. In another study done by Vander Griend et $\mathrm{al}^{21}$ for open reduction internal fixation of HSF by $A O$ plating technique observed two cases of superficial surgical site infections in 32 operated cases. We also observed comparable results in DCP group.

Mahabier et $\mathrm{al}^{22}$ has reported that $48.92 \%$ were managed by non-operative while $51.08 \%$ by operative methods. He reported fall from height as most common mode of injury while we observed rod traffic accidents on top.

\section{CONCLUSION}

Plating of humeral shaft fracture was found to be satisfactory method of treatment with high fracture union rates, better functional outcome [DASH Score] and low complication rate as compared to functional bracing group.

\section{REFERENCES}

1. Tytherleigh-Strong G, Walls N, McQueen MM. The epidemiology of humeral shaft fractures. J Jone Joint Surg 1998;80(2):249-53.

2. Sharma V, Awasthi B, Mehta SM, Babhulkar S. Evaluation of results of different treatment modalities in the management of diaphyseal fractures of the humerus. Internet J OrthopSurg 2010;16: 1531-68.

3. DenardJrA, Richards JE, Obremskey WT, Tucker MC, Floyd M, Herzog GA. Outcome of nonoperative vs operative treatment of humeral shaft fractures: a retrospective study of 213 patients. Orthopedics 2010;33(8)

4. Sarmiento A, Latta $L$. The evolution of functional bracing of fractures. J Bone Joint Surg 2006;88(2):141-8.

5. Sinha A, Kumar S. A retrospective comparative study of plate osteosynthesis and intramedullary nailing in humerus shaft fractures. Int J Orthop 2016;2(2):24-7.

6. Altintas B, Anderson NL, Boykin R, Millett PJ. Operative treatment of torsional humeral shaft fractures in throwers leads to an earlier return to sport: a survey of expert shoulder and elbow surgeons. Knee Surg Sports Traumatol Arthroscopy 2019;27(12):4049-54.

7. Garza-Borjón A, Villarreal-Villarreal G, Tamez-Mata Y, Peña-Martínez V, Simental-Mendia M, Acosta-Olivo C. Humeral shaft fractures: current concept review. Medicina Universitaria. 2019;21(3):113-8.

8. Livani B, Belangero WD. Bridging plate osteosynthesis of humeral shaft fractures. Injury 2004;35(6):587-95.

9. Jiang R, Luo CF, Zeng BF, Mei GH. Minimally invasive plating for complex humeral shaft fractures. Arch Orthop Trauma Surg 2007;127(7):531-5.

10. Hudak PL, Amadio PC, Bombardier C, Beaton D, Cole D, Davis A, et al. Development of an upper extremity outcome measure: the DASH (disabilities of the arm, shoulder, and head). Am J Industrial Med 1996;29(6):602-8

11. Holstein A, Lewis GM. Fractures of the humerus with radial-nerve paralysis. J Bone Joint Surg Am 1963;45(7):1382-8.

12. Huttunen TT, Kannus $P$, Lepola V, Pihlajamäki $H$, Mattila VM. Surgical treatment of humeral-shaft fractures: a register-based study in Finland between 1987 and 2009. Injury 2012;43(10):1704-8.

13. Shaikh SA. Outcome of dynamic compression plating of humerus shaft fracture in adults. J Surg Pak 2019;24(1):2-7.

14. Matsunaga FT, Tamaoki MJ, Matsumoto MH, Netto NA, Faloppa F, Belloti JC. Minimally invasive osteosynthesis with a bridge plate versus a functional brace for humeral shaft fractures: a randomized controlled trial. JBJS 2017;99(7):583-92.

15. Harkin FE, Large RJ. Humeral shaft fractures: union outcomes in a large cohort. J Shoulder Elbow Surg 2017;26(11):1881-8.

16. van de Wall BJ, Ochen $Y$, Beeres FJ, Babst R, Link BC, Heng M, et al. Conservative vs. operative treatment for humeral shaft fractures: a meta-analysis and systematic review of randomized clinical trials and observational studies. J Shoulder Elbow Surg 2020;29(7):1493-504.

17. Serrano R, Mir HR, Sagi HC, Horwitz DS, Ketz JP, Kistler BJ, et al. Modern results of functional bracing of humeral shaft fractures: a multicenter retrospective analysis. J Orthop Trauma 2020;34(4):2069.

18. Lode I, Nordviste V, Erichsen JL, Schmal H, Viberg B. Operative versus nonoperative treatment of humeral shaft fractures: a systematic review and meta-analysis. J Shoulder Elbow Surg 2020; 19(12): 2495-2504.

19. Ali E, Griffiths D, Obi N, Tytherleigh-Strong G, Van Rensburg L. Nonoperative treatment of humeral shaft fractures revisited. J Shoulder Elbow Surg 2015;24(2):210-4.

20. Papasoulis E, Drosos GI, Ververidis AN, Verettas DA. Functional bracing of humeral shaft fractures: a review of clinical studies. Injury 2010;41(7):e21-7.

21. Vander Griend RO, Tomasin J, Ward EF. Open reduction and internal fixation of humeral shaft fractures. Results using $A O$ plating techniques. J Bone Joint Surg Am1986;68(3):430-3.

22. Mahabier KC, Vogels LM, Punt BJ, Roukema GR, Patka P, Van Lieshout EM. Humeral shaft fractures: retrospective results of nonoperative and operative treatment of 186 patients. Injury 2013;44(4):427-30. 